\title{
International Experience and Policy Suggestions for Expanding China's Marine Economic Development Space
}

\author{
Hu Xu-nan ${ }^{1, *}$, Gao Wei-long ${ }^{2}$ \\ ${ }^{1}$ Industrial Economics, School of Economics, Changchun University, China \\ ${ }^{2}$ Industrial Economics, School of Economics, Jilin University, China \\ *Corresponding author: 1194102437@qq.com
}

\begin{abstract}
It is an important strategic deployment for China to expand the development space of China's Marine economy and speed up the construction of a maritime power. Use the literature survey method,The connotation of Marine economy should be clarified, the scientific understanding of Marine economy should be deepened on the basis of learning from the experience of developed countries, and effective measures should be taken to accelerate the development of Marine economy in China. To be specific, it is necessary to formulate a comprehensive Marine master plan, strengthen research and development of core Marine technologies, actively promote emerging Marine industries, build a green Marine ecological environment, innovate and develop modern Marine finance, and deepen and expand international cooperation on the ocean.
\end{abstract}

Keywords. Marine economy, Marine industry, Development space, The government plan.

\section{INTRODUCTION}

The draft of the 14th Five-Year Plan calls for "actively expanding the space for the development of the Marine economy, adhering to the coordination between land and sea, harmony between human and sea, win-win cooperation, coordinated advancement, Marine ecological protection, Marine economic development and protection of maritime rights and interests, and accelerating the building of a maritime power." In recent years, China's Marine economy has developed rapidly. Both the development of major industries of Marine economy and the development of regional Marine economy have maintained steady growth. The industrial scale of Marine economy has been expanding, the industrial structure has been gradually optimized, Marine science and technology has made progress, and Marine products have become increasingly rich. It is estimated that the gross Marine product of China will be RMB 8001 billion in 2020, and the industrial structure will continue to optimize the development trend [1]. However, China's Marine economic development is still relatively backward, with low level of Marine science and technology and low level of industrial development ${ }^{[2]}$. The development of Marine economy is a forward-looking and strategic initiative of China, which determines China's future economic and social development and national defense security. It is of great practical significance that how to make overall planning and solve the above problems according to the experience of developed countries in expanding Marine economic development space.

\section{CONNOTATION DEFINITION OF MARINE ECONOMY}

Marine economy includes the production activities for the development of Marine resources and the dependence on Marine space, as well as the related industrial activities for the direct or indirect development of Marine resources and space. The economic collection formed by such industrial activities is regarded as the category of modern Marine economy. Traditional Marine industries mainly include Marine fishery, Marine transportation, Marine shipbuilding, Marine salt, Marine oil and gas, coastal tourism and so on. Emerging Marine industries mainly include Marine biomedicine industry, seawater comprehensive utilization industry, Marine new energy industry, etc. ${ }^{[3]}$. 


\section{MAJOR PROBLEMS FACING CHINA'S MARINE ECONOMIC DEVELOPMENT}

\subsection{The proportion of China's Marine economy in GDP is relatively low}

According to statistics, the gross Marine product of China in 2015 is 6.553 .4 billion yuan, and the gross Marine product in 2019 is 8941.5 billion yuan ${ }^{[4]}$. Due to the influence of novel coronavirus, the gross Marine product of China in 2020 is RMB 8001 billion ${ }^{[1]}$, as shown in Figure 1. From 2015 to 2020, the average annual growth rate was 4.36 percent. On the whole, China's gross Marine product shows an upward trend.

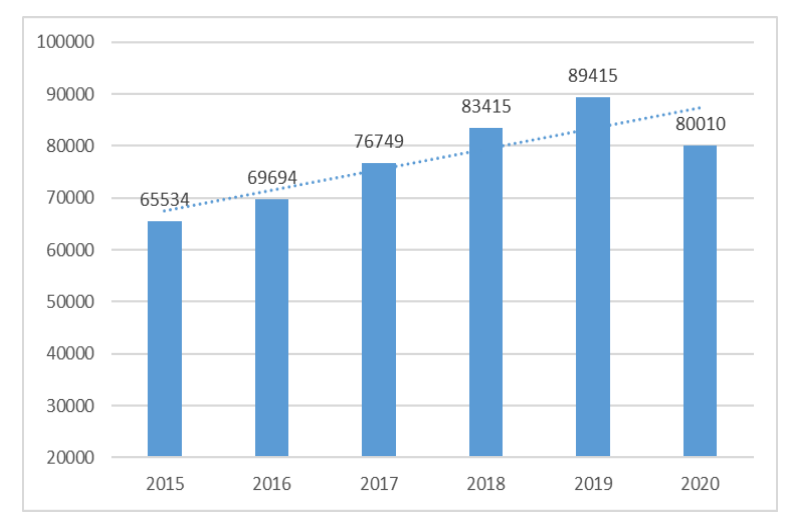

Fig. 1. China's gross Marine product

However, by dividing China's gross Marine product by each year's GDP, the study found that the proportion of China's Marine economy in GDP decreased year by year from 2015 to 2020 .

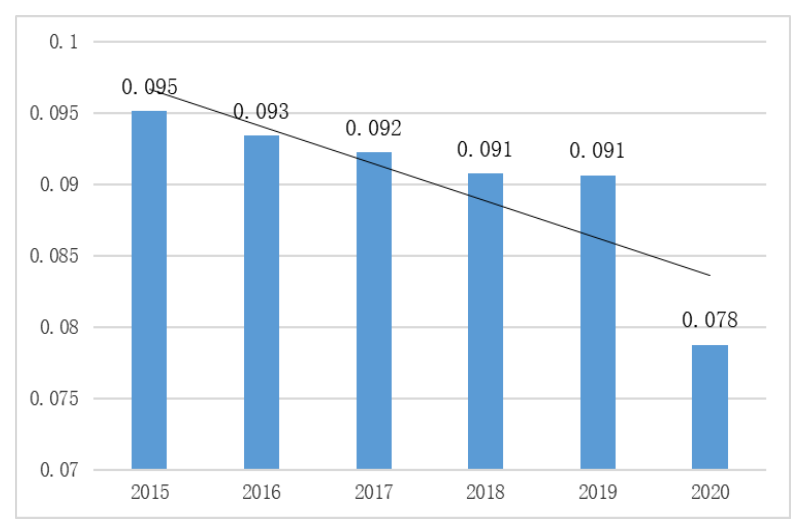

Fig.2. The proportion of China's Marine economy in GDP

\subsection{Emerging Marine industries are still in their infancy}

In 2019, the added value of China's Marine industry reached 3,572.4 billion yuan, of which the Marine fishery, Marine transportation and coastal tourism accounted for 13.2 percent, 18 percent and 50.6 percent respectively of the traditional Marine industries. The proportion of emerging Marine industry is relatively low, and the proportion of Marine biomedicine is only $1.2 \%$, as shown in Figure $3^{[4]}$.

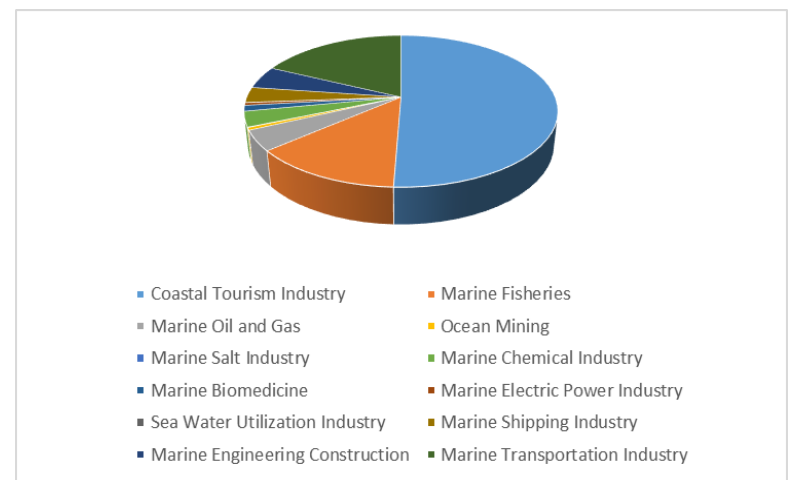

Fig. 3. The proportion of added value of China's Marine industry in 2019

\section{INTERNATIONAL EXPERIENCE IN EXPANDING THE DEVELOPMENT SPACE OF MARINE ECONOMY}

As one of the important parts of modern economy, the Marine economy is playing an increasingly important role in the world. Countries around the world have included the development of Marine economy in major strategic decisions. The author analyzes the experience of the United States, Japan, the United Kingdom, Norway and South Korea in expanding the development space of Marine economy, and summarizes the main realization path of these developed countries to develop Marine economy, which can provide reference and inspiration for China.

\subsection{The United States: advanced in science and technology, strengthening the monitoring and management of resources and environment}

The United States is the world's top maritime power, has advanced the development of Marine economy consciousness. Relying on its strong level of Marine science and technology, China is constantly strengthening the building of its maritime forces. It not only maintains a leading position in traditional Marine technology fields such as ocean exploration, underwater communication and deep-sea resource exploration, but also accelerates the research and development of new generation of Marine technologies such as unmanned autonomous ships, deep submersible robots and underwater cloud computing ${ }^{[5]}$. In addition, the United States has greatly strengthened the monitoring and management of Marine resources and the environment. For Marine resources and Marine environment, the United States government gives priority to the protection and monitoring. Marine pollution shall be 
expressly prohibited, excessive exploitation of fishery resources shall be prevented, and comprehensive protection shall be carried out for coastal river basins and inland river basins entering the sea to ensure the long-term, healthy and sustainable development of Marine resources and Marine environment.

\subsection{Japan: Legislation comes first and government planning is emphasized}

Japan's Marine industry shows a good trend of expanding industrial fields, maturing traditional Marine industries and accelerating development of emerging Marine industries, which is closely related to government planning and regulation. In order to promote the development of Japan's Marine economy, the Japanese government has formulated detailed policy plans and implemented the Marine strategy with the Basic Law on the Ocean, the Basic Marine Plan (2013-
2017) and the Basic Marine Plan (2018-2022) as the core, aiming to provide complete policy support for the development of Japan's Marine economy. Through promulgating a series of policies, laws and industrial planning, the development direction and strategic goal of Marine industry are defined, that is, the goal of establishing a major country in Marine science and technology. Focus on the improvement of Japan's Marine science and technology level, develop Marine high and new technologies, strengthen the in-depth development of Japan's Marine technology and national cooperation, promote the reform of the research and development system, and accelerate the development of emerging Marine industries. The promulgation and implementation of relevant laws and regulations of Marine economy and industrial planning in Japan have effectively promoted the development of Marine economy in Japan ${ }^{[6]}$.

Table 1. Policy planning of developing Marine economy in Japan

\begin{tabular}{c|l|l}
\hline \multicolumn{1}{c|}{ Year } & \multicolumn{1}{|c}{ Policy planning } & \multicolumn{1}{c}{ Purpose } \\
\hline 1997 & 《Ocean Propulsion Program》 & $\begin{array}{l}\text { Developing new and high } \\
\text { Marine technologies }\end{array}$ \\
\hline 1997 & $\begin{array}{l}\text { 《Marine Science and Technology } \\
\text { Development》 }\end{array}$ & $\begin{array}{l}\text { Developing cutting-edge Marine } \\
\text { science and technology }\end{array}$ \\
\hline 2001 & $\begin{array}{l}\text { 《Basic Framework of Japan's } \\
\text { Marine Policy in the New Century》 }\end{array}$ & $\begin{array}{l}\text { To promote development of } \\
\text { Marine science and technology }\end{array}$ \\
\hline 2008 & $\begin{array}{l}\text { 《Basic Law of the Ocean》 } \\
2013\end{array}$ & $\begin{array}{l}\text { To provide a complete } \\
\text { institutional guarantee }\end{array}$ \\
\hline 2018 & $\begin{array}{l}\text { 《Draft Basic Marine Plan》 Ocean Program(2013- } \\
\text { B Basic Ocean Program(2018- }\end{array}$ & $\begin{array}{l}\text { To carry out a basic Marine } \\
\text { survey } \\
\text { Torine economy }\end{array}$ \\
\hline
\end{tabular}

\subsection{UK: Layout emerging industries and develop Marine renewable energy industry}

The UK is rich in offshore wind energy, tidal energy, wave energy and other Marine energies, and the government has invested a lot of funds to support the research and development and industrialization of Marine new energy [7]. Its offshore wind energy industry has matured and is leading the world. The comprehensive and large-scale commercial application of offshore wind energy industry can guarantee the supply of $30 \%$ of the electricity consumption of UK households at low electricity prices, and the price of offshore wind power in the UK hit a new low in 2019 , as shown in figure $4^{[8]}$. Tidal, wave and current power is more stable than wind power, but it is more expensive to develop. The UK government plans to boost research, development and scale up of the offshore renewable energy industry to stabilise the power grid and become carbon neutral. When the traditional Marine industry lost its comparative advantage, the British government accelerated the development of the new Marine industry. 


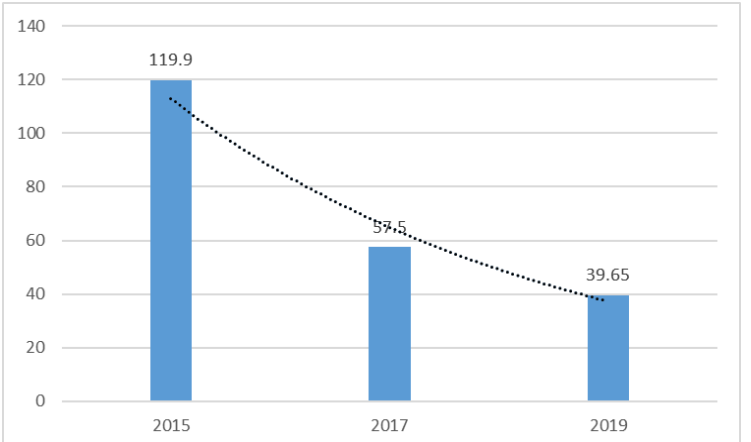

Fig. 4. Tariff levels for offshore wind power in the UK(Pound / megawatt hour)

\subsection{Norway: To develop Marine finance and encourage investment by private enterprises}

In order to promote the development of Marine economy, Marine finance emerged in Norway. Oslo, Norway, mainly provides professional financing services and supporting services, providing stable financial support for the Marine economy. On the premise of market-oriented operation, Norway's Marine finance not only promotes its Marine industry, but also Oslo has become an internationally competitive international financial institution leading New York and Singapore ${ }^{[9]}$. DNB, Norway's state-owned bank based in Oslo, has lent heavily to develop offshore projects and technology on market principles. Moreover, Norway encourages private enterprises to participate in Marine economic and technological development projects, and has a relatively complete private enterprise investment system, aiming to stimulate the enthusiasm of private enterprises in research and development. Guiding diversified subjects to participate in marketoriented operation can not only inject new vitality into research and development, give full play to the market competition mechanism, accelerate the speed of Marine technology research and development, shorten the period of high-tech research and development, but also reduce the burden of national research and development funds, and form a joint force with state-owned enterprises ${ }^{[10]}$.

\subsection{Korea: Establish multi-party cooperation and participate in various conference organizations}

The South Korean government has established maritime partnerships with a number of countries to jointly develop Marine science and technology. South Korea's Ministry of Water Resources, for example, is working with companies in Denmark and Sweden to develop core electronic navigation technology; South Korea and Peru established the Joint Research Center for Marine Science and Technology in 2012. South Korea has established bilateral and multilateral maritime cooperation with other countries in the international market, which has greatly promoted South Korean enterprises to go global. In addition, the South Korean government has actively participated in the organization of international ocean conferences and established cooperative relations of Marine science and technology with many countries to jointly invest and research and develop Marine science and technology, which gives South Korea more opportunities to have close exchanges with the United States, Japan and other countries, and also enhances its international influence. In South Korea, forums on Marine economic development are also held regularly to jointly discuss topics such as Marine science and technology, Marine energy and Marine ecology ${ }^{[11]}$.

\section{POLICY SUGGESTIONS ON EXPANDING THE DEVELOPMENT SPACE OF CHINA'S MARINE ECONOMY}

In light of the successful experience of developed countries in expanding Marine economic space, China should speed up the formulation of a comprehensive Marine master plan, step up research and development of core Marine technologies, actively promote emerging Marine industries, build a green Marine ecological environment, innovate and develop modern Marine finance, and deepen and expand international cooperation on the ocean.

\subsection{Develop a comprehensive Marine master plan}

In 2016, the Chinese government issued the National Marine Development Plan (2016-2020), in which the main objectives of China's Marine economy development were briefly summarized. However, with the increasing importance of Marine economy development, China is in urgent need of formulating a more comprehensive and detailed Marine overall plan. An ocean management system with decentralized management and multiple management leads to inefficiency and delayed decision-making. On the contrary, a centralized, integrated and comprehensive Marine management system can coordinate Marine development planning at the macro level, improve the efficiency of decision-making and management, and fully coordinate the subordinate institutions. Exploring the establishment of the State Oceanic Commission headed by the State Council, that is, the highest department of Marine management, to formulate a comprehensive overall Marine plan ${ }^{[12]}$.

\subsection{Strengthen research and development of core Marine technologies}

The level of Marine technology determines the development speed of Marine economy. High-level 
Marine technology can rapidly promote the development of Marine economy and occupy the position of global Marine power. Low-level Marine technology will restrict the development of Marine economy, unable to adapt to the current trend of Marine technology development, and lose the preponderant advantage. Therefore, the Chinese government should attach great importance to the research and development of core Marine technologies. First, independent research and development of Marine technologies should be strengthened. Centering on cutting-edge Marine technologies, we will strengthen the effective pre-layout of Marine technologies, patents and Marine industry standards, continue to make breakthroughs in Marine core technologies and grasp the opportunities for Marine economic development. Second, cooperate with other countries to develop Marine technologies. Cooperative research and development technology can improve the knowledge spillover of both parties, reduce the risk and uncertainty of independent research and development, and realize complementary advantages and win-win cooperation. Third, while increasing investment in research and development of core Marine technologies, the state encourages enterprises and research institutions to make innovations in Marine technologies. The government can stimulate enterprises' technological innovation through policy incentives, such as reducing the tax burden of $R \& D^{[13]}$.

\subsection{Actively promote emerging Marine industries}

The traditional Marine industry is the foundation and should be paid attention to in any period. However, the cultivation and development of emerging Marine industries is of strategic significance, and the development of national economy is in urgent need of the support of high-tech emerging Marine industries. For example, the Marine biomedicine industry can extract active ingredients from Marine organisms and use them to make various medicines and health care products. The research and development and clinical application of Marine drugs play an important role in anti-cancer and health care. Seawater comprehensive utilization industry can convert seawater into fresh water, which can be used to solve the major problem of fresh water shortage at present. Marine new energy industry can use renewable resources such as ocean tidal energy and wave energy to generate electricity. As the experience of developing Marine renewable energy in the UK shows, it can provide huge power supply capacity and is clean and environmentally friendly. From the above three examples, we can see that the emerging Marine industry involves all aspects of people's production and life, and can effectively improve people's health and living environment. Although some progress has been made in the development of China's emerging Marine industries, there is still much room for progress compared with developed countries.

\subsection{Create a green Marine ecological environment}

In order to ensure the sustainable development of Marine economy, the consciousness of blue ecological civilization should be strengthened, and the protection of Marine ecological environment and the promotion of sustainable development of Marine economy should be taken as the premise of Marine exploitation. We will establish laws and regulations on Marine protection and use a strict legal system to protect the Marine ecological environment. At the same time, we will strengthen green supervision of Marine resources. In order to protect the Marine ecological environment, the United States government has established a scientific and rigorous resource and environmental monitoring and management system to resolutely prevent fishing by draining the water and Marine pollution. China should also adhere to the principle of "paying equal attention to development and protection" in the exploitation of Marine resources, levy Marine ecological tax and raise pollutant discharge charge standard, so as to restrain the behavior of polluters [14]. Moreover, we should accelerate the development of green Marine technology and construct the model of Marine circular economy. Building a green Marine ecological environment is the future development focus of the Marine industry.

\subsection{Innovate and develop modern Marine finance}

The development of Marine economy has high natural risk and market risk, which requires a large amount of capital support. General commercial banks are difficult to meet the capital demand, so it is necessary for the country to construct policy-based finance. Norway's state-owned commercial bank DNB provides a huge loan for the development of Marine economy, which in fact has the nature of policy finance. China should also give priority to promoting policybased finance, and at the same time coordinate the development of commercial finance under the guidance of the government to realize the optimal allocation of resources by the market. Furthermore, the innovative development of the National Marine Trust Fund, angel investment, corporate bonds, asset securitization and other Marine funds can increase the diversified investment and financing mode, expand the social capital sources, reduce the financing cost of enterprises, and effectively promote the technological innovation of enterprises ${ }^{[15]}$. 


\subsection{Deepen and expand international maritime cooperation}

As China's economy takes off, China should actively participate in and deepen international maritime cooperation, establish friendly maritime relations with other countries, jointly research and develop Marine science and technology, expand cooperation space, complement each other's advantages, and upgrade the level of Marine science and technology of both sides. Developed countries, as great maritime powers, are still objects that China should learn from. China will adhere to the international process of opening up and cooperation in the Marine field, actively participate in and host international Marine conferences, strengthen experience exchange with other countries, promote information and knowledge sharing, and enhance its own influence. In China, various conferences and forums on Marine technology and Marine projects should be held regularly to encourage domestic enterprises, universities and research institutions to exchange experiences and learn together through various forms, so as to expand knowledge spillover effect.

\section{CONCLUSION}

With the transformation and upgrading of economic structure, the development of Marine economy has become an important strategic field for all countries to compete for. This paper summarizes the main experiences of developed countries in expanding the development space of Marine economy. The results show that the United States has advanced Marine technology and attaches great importance to the monitoring and management of resources and environment. Japan has enacted a number of important Marine laws and strengthened planning at the government level. Britain is accelerating the deployment of new Marine industries; Norway has established the strongest Marine finance in the world, supporting the development of Marine industry with a large amount of credit. South Korea is actively building multi-party cooperation. In view of the above findings, corresponding policy suggestions are put forward, among which government support and guidance become the primary driving force to expand the development space of Marine economy.

\section{REFERENCES}

[1] China's gross Marine product will exceed 8 trillion yuan in 2020, with a year-on-year decrease of $5.3 \%[\mathrm{~EB} / \mathrm{OL}] .[2021-03-$

31].http:/finance.eastmoney.com/a/2021033118673 92160.html

[2] Zhao Bingqi, Jiang Xiaoyan, Yang Lina. Current situation and countermeasures of Marine economic development in China [J]. China's national conditions and national strength,6(2012)
[3] Baolantoya. Development Status and Trend of Marine Emerging Industries in Rizhao City [A].2010 China Ocean Forum Proceedings [C].2010.

[4] China Marine Economy Statistical Bulletin 2019: Marine GDP accounted for $9.0 \%$ of GDP (attached chart) [EB/OL]. [2020-06-09]. https://www.askci.com/news/chanye/20200609/09 37291161613_2.shtml

[5] Li Yan, Fu Mengzi. A new round of transformation of the US Marine strategy [N]. China Ocean News,2018-12-13(002).

[6] Wu Chongbo, Yao Yungui. The development of Japan's Marine economy and the competition and cooperation with China [J]. Modern Japanese Economy,222(2018)

[7] Wei Youzhou, Du Xiaofeng, Zou Qingping. Research on the latest development status of Marine economy and related industries in UK [J]. Marine Economy,10(2020)

[8] Why UK offshore wind prices keep setting new lows [EB/OL].[2019-09-28]. http://www.sczcjd.com/new.asp?id=3059

[9] The status and experience of developing Marine economy and finance in Norway [EB/OL].[2014$03-$

10].https://www.cnss.com.cn/old/145206_3.jhtml

[10]Meng Shaodong. Marine economy development strategy of developed countries and its enlightenment to China [J]. Hunan Agricultural Sciences, 8(2009)

[11]Sun Yueqi. The development status, policy measures and enlightenment of the Marine economy in South Korea [J]. Asia-Pacific Economics,1(2018)

[12]Sheng Chaoxun, Ren Jiqiu, Xu Jianwei. Research on the ideas and countermeasures of constructing a perfect modern Marine industrial system [J]. Economic Review,4(2021)

[13] Nie Ruichao, Wang Tianchi, Lv Yifan. China's future Marine economic development strategy [J]. Commercial Research,5(2021)

[14]SHEN Hongyi, SUN Jianli. Countermeasures of green Marine economy development in China under the background of "One Belt And One Road" [J]. Business Accounting, 14(2016)

[15]Liu Dongmin, He Fan, Zhang Chunyu, Wu Gui, Feng Weijiang. Marine finance development and China's Marine economic strategy [J]. International Economic Review,5(2015) 